\title{
EL FUNDAMENTO MÍSTICO DE LA JUSTICIA: APORTES DEL ESCEPTICISMO EN MONTAIGNE, HUME, FOUCAULT
}

\author{
Cristina Marta Ambrosini \\ Universidad de Buenos Aires \\ Universidad Nacional de Lanús \\ cristinaambrosini@gmail.com
}

\begin{abstract}
Resumen:
Luego de padecer cruentas dictaduras militares, en América Latina, en las últimas décadas, los debates acerca de la legitimidad del imperio de la Ley y los mecanismos de administración de justicia acaparan el interés de la Filosofía del Derecho. En este trabajo hacemos partícipes de este debate a dos pensadores emblemáticos del escepticismo moderno, Michel de Montaigne y David Hume antes de señalar, como representante contemporáneo, el aporte de Michel Foucault en sus análisis sobre el neoliberalismo. En los cursos editados como Nacimiento de la biopolítica (2007) encontramos categorías de análisis aptas para reflexionar sobre la judicialización de la política, fenómeno adjudicado al embate neoliberal en la región.
\end{abstract}

\section{Palabras Claves:}

Escepticismo, fundamento místico, biopolítica, neoliberalismo, judicialización.

\begin{abstract}
:
After suffering bloody military dictatorships in Latin America in the last decades, debates about the legitimacy of the rule of law and the mechanisms of administration of justice dominate the interest of the Philosophy of Law. In this paper, we bring together two emblematic thinkers of modern skepticism, Michel de Montaigne and David Hume, before pointing out, as a contemporary representative, the contribution of Michel Foucault in his analysis of neoliberalism. In the courses published as The Birth of Biopolitics we find categories of analysis suitable for reflecting on the judicialization of politics, a phenomenon adjudicated to the neoliberal struggle in the region.
\end{abstract}

\section{Keywords:}

Skepticism, Mystical foundation, Biopolitics, Neoliberalism, Judicialization. 
Recibido: 19/01/2017

Aceptado: 21/02/2017

\section{EL ÁRBOL DE LA JUSTICIA}

La justicia es una virtud capital sin la cual se hace imposible el orden social, de allí que su representación, a través de un palo plantado en la tierra, fue uno de los primeros actos solemnes en la fundación de toda nueva ciudad en la colonización de América por parte de los españoles. En la segunda fundación de Buenos Aires, el 11 de junio de 1580, Juan de Garay, como era mandato real, implantó el orden jurídico e hizo instalar una picota o árbol de la Justicia, símbolo de la que se impartiría en nombre de S.M. el Rey de Castilla y de las Indias. La Plaza de Mayo, desde entonces hasta mediados del s. XIX, funcionó como lugar de cumplimiento de castigos públicos y de ejecuciones. El fusilamiento, descuartizamiento y colgamiento de los reos, lejos de escandalizar a los vecinos, los congregaba para presenciar un espectáculo que se consideraba moralizante. Los actos de justicia legal eran acontecimientos públicos, se efectuaban en presencia de las más altas dignidades políticas y religiosas. Los escolares, espectadores obligados, eran ubicados en un lugar preferencial para que no perdieran detalle y a quienes el profesor, antes y después de la ejecución, instaba a hacer las reflexiones pertinentes. Durante la ejecución, las campanas de las iglesias tocaban "a agonía" y, después de ejecutados los delincuentes, tocaban "a muerto". Normalmente, los reos ejecutados eran malvivientes vulgares, sin familias que se hicieran cargo del cadáver por lo que algunos miembros piadosos de las cofradías salían a pedir limosnas "para sufragios del alma del reo que se va a ejecutar". De este modo, la justicia humana cobraba su deuda en nombre de la sociedad ofendida mientras la justicia divina cuidaba de salvar el alma arrepentida del delincuente (De La Fuente Machain, 1973). Cabe destacar que en estos confines australes de la corona española, la aplicación de la justicia no contaba con el boato y la espectacularidad de las grandes ciudades europeas donde, desde la hoguera hasta las distintas formas de ahorcamiento, la presencia del pueblo en el ajusticiamiento en las plazas públicas era uno de los modos de participación cívica y del reconocimiento de la presencia de un orden jurídico que preservara el cumplimiento de reglas. Estas "costumbres" resultarían hoy en día aberrantes, la aplicación de justicia está mediada por otros mecanismos pero no por eso resulta más humanitaria y menos cuestionable. Como bien advierte Agnes Heller en su ya clásico libro Más allá de la justicia (1990), hay un límite muy delgado entre la justicia y la crueldad puesto que en su concepción formal la justicia es una virtud fría, representada como una diosa que porta en una mano una espada y en la otra una balanza indicando que en sus decisiones debe equilibrar el orden social y cuidar su estabilidad. A menudo la diosa lleva una venda en los ojos ya que no debe ver a aquellos que alcanza con su castigo. El velo en los ojos representa la exigencia de imparcialidad. Los romanos afirmaban "fiat justitia pereat mundus", con lo que representaban esta máxima exigencia de imperturbabilidad frente al accionar del Estado para hacer cumplir las normas del Derecho. En algunas interpretaciones radicales de este mandato moral, la justicia tampoco está separada del fanatismo que se presenta cuando los grupos políticos o religiosos interpretan las 
normas o reglas propias de manera unilateral y absoluta, sin considerar las reglas o normas de otros grupos. Advierte Agnes Heller que el concepto formal de justicia necesita complementarse con un contenido ético-político donde lo que se considera moralmente bueno y virtuoso se define en conjunción con un orden político proyectado como justo (1990: 67). Esto habilita al pensamiento filosófico para dar respuesta a la necesidad de una fundamentación no solamente jurídica sino ética de la justicia ya que es necesario limitar la posibilidad de que la fuerza de la ley en la aplicación de la justicia se transforme en violencia e injusticia. Como sabemos, las relaciones entre el Derecho y la Justicia, entre la Ley y las prácticas que la hacen cumplir, son problemáticas y, una vez roto el vínculo entre la justificación religiosa y la justificación ética de la Justicia, tal relación pasó a ser conflictiva.

En la primera modernidad, para la misma época en que Garay plantó el árbol de la justicia en la recién fundada ciudad de Buenos Aires, en otra ciudad de Francia, específicamente en Bordeaux, Michel de Montaigne (1533-1592), reflexiona acerca de la tensión entre la fuerza de la Ley y la legitimación de la Justicia. La "actitud pirrónica" reaparece con fuerza en esta época a partir de las traducciones latinas de los escritos de Sexto Empírico y, sobre todo, a partir del clima de fuertes disputas religiosas y del choque entre actitudes reformistas y conservadoras dentro de la Iglesia católica. Una vez desencantada la teocracia, como fundamento del orden jurídico, aparece la preocupación por el fundamento del orden legal y desde un escepticismo radicalizado, Montaigne nombra el tabú: denuncia que la justicia puede ser injusta y que en muchos casos los crímenes cometidos por la justicia son más aborrecibles que los cometidos por los delincuentes. A continuación presentaremos estas ideas de Montaigne para ver su proyección sobre el pensamiento político posterior, en especial sobre David Hume. Finalmente, a la luz de estas ideas, esperamos tener elementos para resignificar el lugar de la justicia en nuestras sociedades frente al embate neoliberal y sus innovaciones en el campo del Derecho. Para ello aludiremos a los análisis de las últimas lecciones de Michel Foucault, específicamente las de febrero de 1979 compiladas bajo el título Nacimiento de la biopolítica para identificar en el concepto de biopoder el mismo enfoque que revela a la Justicia como un dispositivo del poder, principal herramienta de sujeción, que en el neoliberalismo intensifica su intervención para criminalizar y judicializar la política.

\section{EL ESCEPTICISMO DE MONTAIGNE}

El escepticismo tiene un tratamiento reducido en los manuales de Filosofía. Normalmente, los historiadores exageran los aspectos negativos de la crítica escéptica a la vez que insisten en destacar la imposibilidad, desde esta actitud, de fundamentar la ética y la política. La importancia de Montaigne y su incidencia en la conformación del pensamiento político moderno no es reconocida en su verdadera dimensión tampoco en el campo de la filosofía francesa. Un caso digno de destacar es el de Jacques Derrida, que retoma en temas políticos, centralmente en los valores de la hospitalidad y la amistad, la necesidad de "deconstruir" la filosofía política contemporánea y para ello acude a las ideas de Montaigne frecuentemente. En una conferencia dictada en octubre de 1989 que luego aparece publicada como Fuerza de ley. El fundamento místico de la autoridad (Derrida, 1992) revisa las relaciones conflictivas entre justicia y derecho en el pensamiento moderno en vista a una 
paradoja que ya habría advertido Montaigne en el intento de justificar el uso de la fuerza de la ley cuando se trata de limitar la libertad humana. ¿Cuándo la fuerza legal es justa o es violenta? Montaigne se ocupa de este tema en el Libro III, capítulo XIII "De la experiencia" en Ensayos (Montaigne, 2011), donde advierte sobre la dificultad para encontrar principios firmes donde asentar el deber particular y más aún, cuando se trata de legislar. La justicia que nos rige, dice, es un verdadero testimonio de la flaqueza humana con tantos errores y contradicciones que presenta. "¿Cuántas condenas he visto más criminales que el crimen?" (Montaigne, 2011: 959) Luego de revisar la posición de los estoicos, los cirenaicos y con ejemplos tomados hasta de China, expresa:
Las leyes mantienen su crédito no porque sean justas, sino porque son leyes. Este es el fundamento místico de la autoridad: no tienen otro, cosa que les sirve de mucho. A menudo están hechas por tontos. Más a menudo, por gentes que por odio a la igualdad carecen de equidad. Pero siempre por hombres, autores varios y vacilantes [...]. Quien las obedece porque son justas no las obedece por donde debe (Montaigne, 2011: 959-960).

Aquí destaca Derrida el uso del término "crédito" ya que alude a un acto de confianza, de fe. El fundamento de la autoridad no es racional, por el contrario, se basa en una creencia, en una convicción o sentimiento inexpresable por el lenguaje. Aquí la alusión al carácter "místico" parece acercarse al sentido que le dará Wittgenstein a lo místico, a lo que queda afuera de los límites del lenguaje pero que, siendo infundado, a la vez, es fundante de significados. Este fundamento infundado de la autoridad, por su parte, es fundante de obligaciones y derechos (Derrida 1992). En apoyo de estas ideas Derrida nos remite al Libro XII de los Ensayos, a la famosa "Apología de Raimundo de Sabunde" donde Montaigne afirma que las leyes adquieren autoridad por la aceptación y el uso.

Es peligroso remontarlas a su nacimiento, pues aumentan y se ennoblecen al andar, como nuestros ríos; si se las sigue aguas arriba, no son sino un pequeño manantial de agua apenas reconocible que se enorgullece y fortifica al envejecer (Montaigne, 2011: 533).

Montaigne alude al poder de la imaginación para crear "ficciones legítimas" que justifiquen la justicia de la ley o la verdad de las ciencias recurriendo a la idea de "artificio" o "suplemento" en una peculiar analogía con las mujeres que "inventan" una belleza o perfección que no tienen con "prótesis" artificiales de marfil, algodón o fieltro para ostentar aquello de lo que carecen.

Así como las mujeres usan dientes de marfil allí donde los suyos naturales faltan, y en lugar de su verdadero color se hacen uno con alguna materia ajena; así como se hacen muslos de paño y fieltro y curvas de algodón, y a la vista de todos se embellecen con una belleza falsa y prestada, así hace la ciencia (e incluso el derecho, dicen, tiene ficciones legítimas sobre las cuales funda la verdad de su justicia) y nos da en pago y como presupuestos las cosas que ella misma nos informa que han sido inventadas pues esos epiciclos, excéntricos, concéntricos, con los que la astrología se ayuda a conducir el movimiento de las estrellas, nos lo ofrece como lo mejor que ha podido inventar en ese tema (Montaigne, 2011: 489). 
Para Montaigne, la filosofía no nos dice lo que es ni lo que cree sino lo que fabrica, anticipando ideas que fructificarán en los siglos XIX y XX acerca del uso de "ficciones legítimas" incluso en el Derecho. En el capítulo XXII "De la costumbre, y de no cambiar fácilmente una ley aceptada" presenta a las costumbres como una fuerza de autoridad.

Pues la costumbre es una maestra de escuela violenta y traidora (Montaigne, 2011: 110).

Montaigne cita costumbres extrañas como algunas de los habitantes de las "nuevas Indias" de comer arañas, hormigas o murciélagos ya que nos escandalizan las costumbres de otros como exóticas o descabelladas, pero podemos advertir que lo que hacemos todos los días también "embota los sentidos" y lo aceptamos como natural por imperio del acostumbramiento. También nos advierte acerca de la importancia del control en la educación de los niños, especialmente en el control de sus juegos para impedir que se instalen hábitos perniciosos. Así afirma: "desde mi infancia me acostumbré a seguir un camino abierto y llano y a disgustarme de mezclar trampa o astucia en mis juegos" (Montaigne, 2011: 111). Montaigne dedica numerosas páginas, en este capítulo, a relatar costumbres distintas en distintas comunidades para concluir con una frase que nuevamente podríamos adjudicarle a Wittgenstein cuando afirma "los límites de mi lenguaje significan los límites de mi mundo" (Wittgenstein, 2004: 111), ya que aquí sostiene:

De donde sucede que aquello que cae fuera de los límites de la costumbre se considera fuera de los límites de la razón (Montaigne, 2011: 116).

Alude a Platón cuando recomienda reforzar la validez y vigencia de algunas costumbres (la prohibición de los amores desnaturalizados o contra natura) frente a la opinión pública, recurriendo a los poetas para infundir miedos al contar historias terribles en quienes no respetan las buenas costumbres. Las fábulas de Tiestes, Edipo, Macario, serían ejemplos de este tipo por sus efectos moralizantes acerca de las graves consecuencias que acarrea la transgresión de las costumbres aceptadas por la comunidad y consagradas como leyes. En estos pasajes, Montaigne se presenta como un conservador, cuando abre sospechas acerca de los intentos de innovar en materia de leyes frente al peligro de alterar el orden vigente o al menos la necesidad de prudencia o sensatez. Dado el impacto negativo que producen estos cambios "es muy dudoso que cambiando una ley aceptada tal cual, se pueda obtener un beneficio tan importante como la dificultad de eliminarla. Porque un Estado es como una construcción hecha de piezas diversas unidas por tal relación que es imposible mover una sin que todo el cuerpo lo sienta" (Montaigne, 2011: 119).

Los que trastornan un estado son con frecuencia los primeros afectados por su ruina (Montaigne, 2011: 120).

La posición de Montaigne respecto a la autoridad de las leyes parece provenir de una posición pragmática al advertir acerca de un equilibrio entre costos y beneficios, ya que toda alteración del orden vigente podría introducir el caos y la anarquía y, por lo tanto, perjudicar antes que beneficiar la vida social. Montaigne reconoce que el orden social se sustenta en la necesidad de imponer un orden que "obligue" a las personas a respetar la vida y las propiedades de los demás y que el Estado es necesario 
dada la precaria o frágil capacidad de los humanos de convivir pacíficamente en ausencia de la fuerza de una autoridad. La imposición de la autoridad de la Ley debe tener la suficiente fuerza como para conjurar el mal mayor que es la anarquía, el desorden y la insurrección generalizada.

\section{El OtRO ESCÉPTICO: DAVID HUME}

En los manuales de filosofía Hume es presentado como un autor asociado al pensamiento inglés a pesar de su origen escocés. Según Maclntyre (1994: 275) esto se debe a que él mismo experimentó un giro "anglicanizante" a la edad de 20 años y, en su intento de transformarse en un caballero inglés, cambió la ortografía de su apellido de "Home" a "Hume". Sin desconocer esta impronta histórica, aquí intentamos mostrar su pertenencia a otra tradición, la del escepticismo francés. Para ello comenzamos por señalar que Hume, en 1734, tras unos meses en Bristol, dejó el estudio autodidáctico y realizó "experimentos mentales" en La Flèche (Anjou, Francia). En territorio francés y en contacto con el campo de debates de la filosofía francesa completó el Tratado de la naturaleza humana (2000) a la edad de veintiséis años. Recordemos que La Flèche fue una escuela que fundó Enrique IV en 1603, puso a cargo a los jesuitas y en ella se educó Descartes durante 6 años, desde los 10 a los 16 (desde 1606 hasta 1612). Según Mac Intyre (1994: 279) el autor que impacta sobre Hume en los planteos escépticos de la época es Pierre Bayle (1647-1706), un hugonote que publicó sus críticas a la intolerancia religiosa en Holanda ya que debió huir de Francia por la persecución política. En Bayle, la lucha contra la escolástica se da en el terreno religioso y, al modo de Montaigne, concentra sus críticas en la actitud dogmática de la teología racionalista pero ahora en el lenguaje erudito y preciso donde el Ensayo, de carácter autobiográfico, propio de la época de Montaigne, deja paso al Diccionario, género asociado a una etapa madura de la elaboración académica. La obra de Bayle que causó impacto en Hume fue el Diccionaire historique et critique, publicado por primera vez en 1697. Al parecer, en el contacto con esta obra, Hume accede a una elaboración académica y rigurosamente filosófica de la vertiente escéptica que, en distintas dosis de pirronismo, impregnó el pensamiento francés desde los inicios del Renacimiento y la primera Modernidad y desde allí irradió al resto de Europa. En base a estos antecedentes afirmamos que el punto de partida escéptico caracteriza la concepción de la justicia en Hume. Como bien observó, plantear una teoría de la justicia implica aceptar que las necesidades humanas no están satisfechas, cualesquiera que ellas sean, y que habrá una tensión ineliminable entre el acatamiento a la ley y las demandas por cumplir las necesidades insatisfechas. Descarnadamente, Hume elude encontrar el refugio de la razón para recurrir a una naturaleza preexistente a la vida social, ya sea recurriendo a la teología o al contractualismo al momento de justificar la autoridad de la ley.

En el Libro III del Tratado de la naturaleza humana (Hume, 2000), lo dedica a tratar temas de Ética y Política que resultan cruciales para dilucidar las condiciones del orden social. Al igual que Montaigne, comienza comparando la endeble y deplorable condición del hombre en comparación con el resto de los animales y la necesidad de crear "artificios" que le permitan superar estas limitaciones. El remedio a las carencias humanas no proviene de la naturaleza sino del artificio. Los filósofos aluden al estado de naturaleza, dice Hume, en tono crítico, pero este estado no puede interpretarse 
más que como una ficción, no distinta de la edad de oro que inventaron los poetas. La justicia se origina en las convenciones humanas que intentan remediar las condiciones dadas por la conjunción de dos factores: el egoísmo moderado y la escasez de recursos. El Estado también es un artificio, una invención necesaria para la humanidad. Mientras dura un estado de concordia y amistad en una comunidad nadie se somete a la autoridad de un compañero, dice Hume, pero si se produce un estado de guerra entonces un jefe goza de un simulacro de autoridad que desaparece cuando se restituye la paz. De allí que los gobiernos al principio son monárquicos y las repúblicas solamente surgen de los abusos de la monarquía y del poder despótico (Hume, 2000: 109). Los filósofos, al buscar el origen de la obediencia a la ley civil, se remontan hasta este oscuro inicio, niegan que sean invenciones artificiales y, a su vez, les incorporan otros deberes que son todavía más artificiales. Los funcionarios se ocupan de ocultar, sobre todo al vulgo, el origen artificial de la justicia (Hume, 2000: 109). Hume reconoce que es imposible mantener una sociedad sin justicia y sin la observancia de las tres leyes fundamentales relativas a la estabilidad de las posesiones, la transferencia por consentimiento y el cumplimiento de las promesas. Estas leyes son anteriores al gobierno e imponen una obligación anterior al cumplimiento de las órdenes de los magistrados civiles.

Iré más lejos aún y afirmaré que es natural que se suponga que el gobierno, al establecer por primera vez, deriva su autoridad de esas leyes de naturaleza y en particular de la que se refiere al cumplimiento de las promesas. Una vez que los hombres han percibido la necesidad del gobierno para mantener la paz y ejecutar la justicia, se reunirán naturalmente, elegirán magistrados, determinarán su poder y les prometerán obediencia (Hume, 2000: 110).

De acuerdo con Hume, el único fundamento sobre el que puede legitimarse la propiedad privada es la ventaja mutua, ya que es más ventajoso respetar las posesiones de los otros y para asegurar la continuidad de este respeto por las posesiones de los otros, eleva este sentimiento a la categoría de virtud. La propiedad y la desigualdad de propiedades son justas porque son útiles, salvo en los casos de absoluta abundancia o de absoluta escasez. Podemos hablar de justicia allí donde la cuestión concierne a la distribución de una cantidad limitada de bienes. Otra de las condiciones de la justicia, en Hume, es el egoísmo moderado dado que, si los hombres fueran sinceramente altruistas nunca se hubiesen planteado la necesidad de adoptar reglas restrictivas de la libertad y si persiguieran su propio interés sin ningún tipo de interés común, caerían la violencia sin conciencia de culpa.

He aquí una proposición que pienso que puede considerarse cierta: que sólo del egoísmo y de la limitada generosidad de los hombres, junto con los escasos recursos con que la naturaleza lo ha provisto para sus necesidades, deriva la justicia (Hume, 2000: 64).

En el artículo "Del origen del gobierno" (Hume, 2010) reconoce, al modo de Montaigne, pero en el contexto de un planteo consistente y más elaborado, la presencia de una tensión ineliminable entre la autoridad de la ley y la libertad de las personas, una lucha ineludible puesto que no puede aconsejarse la victoria de una parte sobre la otra. 
En todos los gobiernos hay siempre una lucha intestina, declarada o secreta, entre la autoridad y la libertad. Ninguna de ellas puede prevalecer absolutamente en la lucha (Hume, 2010: 77).

Una vez que los hombres inventaron las tres leyes fundamentales de la naturaleza advirtieron la necesidad de asegurar su subsistencia limitando sus apetitos naturales. El mismo egoísmo produce las reglas de la justicia y es el primer motivo del acatamiento al orden que impone (Hume, 2000: 112).

En este sentido debe admitirse que la libertad es la perfección de la sociedad civil pero que sin embargo hay que reconocer a la autoridad como esencial para su propia existencia (Hume, 2010: 78)

La vida social se sigue del acatamiento y el seguimiento de reglas que se aceptan bajo la necesidad de limitar el egoísmo, asegurar la propiedad y la autoconservación. Luego, la fuerza de los hábitos y las costumbres legitiman estas reglas hasta darles obligatoriedad. Las reglas están presentes en la vida social y es necesario seguirlas para evitar las calamidades de la anarquía y limitar la violencia de los congéneres. Ahora ¿esto implica entregarse atado de pies y manos a la obediencia civil? Hume es terminante: "en ninguna de nuestras nociones de moral sostenemos el absurdo de la obediencia pasiva" (2000: 123).

Hume rechaza, tachando de falaz y sofístico, el argumento contractualista que presupone una promesa o contrato original como origen del acatamiento al gobierno y justifica la liberación de este acatamiento cuando el gobernante es tiránico. Estos autores suponen un compromiso mutuo entre el gobernante y los gobernados de tal modo que los segundos quedan liberados de sus promesas y retornan al estado de libertad cuando la otra parte traiciona el pacto. Hume pretende llegar a una conclusión semejante pero desde otro punto de partida, el de la necesidad de convención en vista a algún interés, el de la presencia de reglas sociales que dan lugar a la virtud de la justicia:

Advierto que la promesa misma surge totalmente de las convenciones humanas y se inventa con vistas a un cierto interés. En consecuencia, busco un interés semejante más inmediatamente vinculado al gobierno y que pueda ser a la vez el motivo de su institución y la fuente de nuestra obediencia a él. Hallo que ese interés consiste en la seguridad y protección de que gozamos en la sociedad política y que jamás podemos alcanzar cuando somos plenamente libres e independientes. Por consiguiente, como el interés es la sanción inmediata del gobierno, éste no puede existir por más tiempo que aquel; y toda vez que el magistrado civil lleva su opresión al punto de hacer su autoridad absolutamente intolerable, no estamos ya obligados a someternos a ella. Cuando cesa la causa debe cesar también el efecto (Hume, 2000: 121).

Por un lado la obediencia responde al cumplimiento de reglas a las que no conviene ponerle excepciones ya que esto las debilita y las vuelve inestables pero tampoco puede absolutizarse el carácter de la regla hasta anular la posibilidad de mostrar la necesidad de excepciones en vista a la deplorable condición humana, tan 
proclive a pervertir las instituciones y transformar a los gobernantes en tiranos y enemigos públicos:

El gobierno es una mera invención humana para el interés de la sociedad. Cuando la tiranía del gobernante elimina ese interés, elimina también la obligación natural de obediencia. La obligación moral se funda en la natural y en consecuencia debe cesar cuando ésta cesa (Hume, 2000: 124).

Advertimos con Hume que cuando ni Dios ni la Razón Universal sirven de fundamento, de todos modos hay reglas que permiten regular la vida social. Como nos muestra Kant, Hume supone un punto de no retorno: el final del sueño dogmático. La certeza, como la ingenuidad, es imposible de recuperar una vez que se pierde. Hume supone la pérdida de la ingenuidad del racionalismo platónico y la pérdida de las certezas acerca de la existencia de verdades absolutas, pero no el aniquilamiento de la filosofía (Bermudo, 1983: 18). Por el contrario, la razón, liberada de las ataduras dogmáticas, se reconoce productora de reglas.

\section{BIOPODER Y CRECIMIENTO DE LA DEMANDA JUDICIAL}

En Sujeto y el Poder (1982) Foucault alude a los últimos 20 años de su obra para ubicar allí los temas centrales de preocupación donde alude al Iluminismo y propone dirigir la atención hacia las formas de resistencia al poder, utilizando la resistencia como "catalizador". Afirma que, en los últimos 20 años, su trabajo se concentró en las formas de sujeción, ya que entiende que cada vez son más importantes las luchas contra la sumisión de la subjetividad, cuando las luchas contra la explotación aún no han terminado.

Por lo tanto no es el poder sino el sujeto, el tema general de mi investigación (Foucault, 1982 s/p).

En este texto, siguiendo la idea de indagar acerca de los vínculos entre el poder y los mecanismos de individuación, alude a Kant como un ejemplo, antes que Hegel y Nietzsche, en vista a encontrar antecedentes en el esfuerzo por develar la particularidad del momento histórico, el evento reciente, incluso contemporáneo con la pregunta ¿Qué es la Ilustración? En vista a hacer una genealogía del tema indaga acerca de ¿qué nos está pasando en este mismo momento?, ¿qué somos? Respecto a una idea anterior, asociada y quizás antecedente del de "minoría de edad", la de "servidumbre voluntaria" de Étienne de La Boétie, afirma Foucault:

El problema crucial del poder no es aquel de la servidumbre voluntaria. (¿Cómo podríamos desear ser esclavos?). En el corazón mismo de las relaciones de poder y constantemente provocándolas, están la resistencia de la voluntad y la intransigencia de la libertad (Foucault, $1982 \mathrm{~s} / \mathrm{p}$ ).

Las relaciones entre servidumbre voluntaria y dispositivo biopolítico han sido motivo de debates en los últimos años (D’Odorico 2011). Las distintas formas de las tiranías (económicas, sociales, informáticas) evidencian distintos modos de violentar el supuesto moderno de la libertad y el concepto de "biopoder" resulta fértil para revisar los modos de "sujeción" actuales donde se dan las "luchas" entre las distintas formas de obediencia y resistencia. La "servidumbre voluntaria" sigue siendo un 
nombre apto para ubicar nuevas formas de la voluntad de servir, la que, como ya nos dijo La Boétie, no deja de ser un "innombrable", un misterio, un punto ciego, algo que queda en el terreno de lo "místico" y que rehuye a una fundamentación. Montaigne, el alter ego de La Boétie, lo llamó "el fundamento místico de la ley". En este texto, Foucault alude a La Boétie, el amigo prematuramente muerto de Montaigne, el que aparece nombrado en otras obras, específicamente en Dichos y Escritos, en Historia de la locura en la época clásica y en La hermenéutica del sujeto (Castro 2004: 245). Respecto a sus ideas sobre la biopolítica, sus lecciones sobre este tema se conocieron en estos últimos años y reúnen las lecciones impartidas entre enero y abril de 1979, donde se alude al ordoliberalismo alemán y al neoliberalismo norteamericano de la Escuela de Chicago. Foucault se interesa por el análisis del liberalismo no como una teoría o una ideología sino como una práctica, como una manera de actuar que irá mutando hasta transformarse en una novedosa racionalización del gobierno, especialmente en las décadas siguientes a la finalización de la Segunda Guerra Mundial hasta los años 70 y 80 en que está dictando sus cursos. La cuestión consiste en atender al liberalismo como gobierno de las conductas y las novedades introducidas en las últimas décadas del curso. En la clase del 21 de febrero de 1979, alude Foucault al crecimiento de la demanda judicial al indicar que con el neoliberalismo alemán cambian las ideas acerca de la función de La Ley y de las funciones legislativas bajo el presupuesto de que el Estado es un prestador de reglas de juego para la competencia (Mendez, 2015: 279). En este curso retoma el tema del neoliberalismo alemán que reclama por una economía de mercado, pero a la vez por una política social activa, omnipresente e intervencionista, no para compensar las posibilidades de desigualdades sociales sino para garantizar el funcionamiento de la competencia. Para ello, señala Foucault, es necesaria una redefinición de la institución jurídica y de las reglas del Derecho necesarias para garantizar la economía competitiva del Estado. El "intervencionismo jurídico" (Foucault, 2007:199) constituye una innovación dentro del capitalismo donde lo que se busca es el mínimo intervencionismo económico bajo el supuesto de que no hay que tocar las leyes del mercado pero sí intervenir jurídicamente para que esta leyes se cumplan y con ello se consiga la regulación social.

Entonces ningún intervencionismo económico o el mínimo de intervencionismo económico y el máximo de intervencionismo jurídico. (Foucault, 2011: 199).

En este nuevo capitalismo, el sujeto económico ya no es el hombre, el consumidor, ni el productor sino las empresas que, cuanto más se desarrollen, más puntos de fricción y conflicto aparecerán. Esto producirá una mayor demanda judicial para actuar como árbitro en el cumplimiento de las reglas de juego.

En suma, cuanto más formal es la Ley, más amplia es la intervención judicial. Y cuanto más se formalizan las intervenciones gubernamentales del poder público y más retrocede la intervención administrativa, la justicia tiende a convertirse, y debe convertirse, en un servicio público omnipresente (Foucault, 2011: 212).

En estas últimas décadas, el esclarecedor análisis del neoliberalismo, por parte de Foucault, resulta revelador para desentrañar el sentido de algunas innovaciones 
sociales que adjudicamos al embate neoliberal, aunque vemos que los efectos perniciosos de estas innovaciones, a su vez, son el resultado de nuevas mutaciones institucionales. Para la época de los teóricos del ordoliberalismo, la demanda judicial estaba orientada a evitar los monopolios y las concentraciones de poder económico en pocas manos para garantizar la libre competencia. Hoy en día parece ocurrir lo contrario, ya que el poder judicial aparece como un instrumento de presión destinado a jaquear y criminalizar la política. Los Ilamados "golpes blandos", destinados a cumplir la misma finalidad que los golpes de Estado tradicionales, ya no recurren a las Fuerzas armadas sino a distintos dispositivos donde la crimininalización y judicialización de los actos políticos son un elemento decisivo de desestabilización. De todos modos, es necesario admitir que la participación activa del aparato judicial en cuestiones políticas puede tener un costado defendible, que se presenta cuando permite vehiculizar demandas ciudadanas, lo que habría que distinguir de cuando se utiliza por grupos de poder (económicos, sociales o políticos) como elemento de presión para imponer sus intereses (Palacios et al 2007: 31). Como toda innovación, la judicialización de la política puede tener efectos de emancipación, para hacer valer los derechos de los ciudadanos frente al Estado o pueden representar nuevas formas de servidumbre y sujeción. Como bien nos advierten tanto Montaigne como Hume y Foucault, todo intento de fundamentación y legitimación teórica de la justicia es el esfuerzo de inventar una ficción más. No se trata de develar la pregunta ¿qué es la justicia?, sino de tratar de entender en cada caso qué permite y qué prohíbe, cómo funciona. No se trata tampoco de rechazar las posiciones deontológicas asociadas a algún concepto formal de justicia. La imparcialidad de la justicia es un desiderátum, es una exigencia central para garantizar la igualdad ante la Ley, un valor central de las sociedades democráticas que debe ser acompañada por una comprensión ética. Lejos de rechazar este valor, de lo que se trata es de mostrar que en muchos casos el valor de la imparcialidad es instrumentalizado y vulnerado en nombre de una supuesta neutralidad que encubre la presencia de intereses de dominación.

\section{BIBLIOGRAFÍA}

BERMUDO, José Manuel (1983). El empirismo. De la pasión del filósofo a la paz del sabio. Barcelona: Montesinos.

CASTRO, Edgardo (2004). El vocabulario de Michel Foucault. Quilmes: PrometeoUniversidad de Quilmes.

D’ODORICO, Gabriela (2011). La "naturaleza humana" como dispositivo biopolítico. La utilización de lo humano en la política contemporánea (Tesis inédita de Doctorado). Buenos Aires: Facultad de Ciencia Sociales.

DE LAFUENTE MACHAIN, Ricardo (1973). La plaza trágica. Cuadernos de Buenos Aires XVII. Buenos Aires: Municipalidad de la Ciudad de Buenos Aires.

DERRIDA, Jacques (1992). "Fuerza de Ley. El fundamento místico de la autoridad", Doxa. Cuadernos de Filosofía del Derecho, 11, pp. 129-191. Disponible en http://www.cervantesvirtual.com/obra/n-11---1992/. 
FOUCAUL, Michel (1982). "Sujeto y el Poder". Revista Hoja de Ruta, s.p.i. Disponible en http://www.hojaderuta.org/imagenes/foucault.pdf (consultado 05/12/2016).

- (2007). Nacimiento de la Biopolítica. Buenos Aires: Fondo de Cultura Económica.

HELLER; Ágnes (1990). Más allá de la justicia. Barcelona: Crítica.

HUME, David (2010). Ensayos morales y políticos. Buenos Aires: Losada.

- (2000). Tratado de la naturaleza humana. Buenos Aires: EUDEBA.

MACINTYRE, Alasdayr (1994). Justicia y racionalidad. Barcelona: EIUNSA.

MENDEZ, Pablo (2015). "Foucault: un pensamiento de los umbrales. De las sociedades de normalización al neoliberalismo", (Tesis inédita de Doctorado). Departamento de Humanidades y Artes, Universidad Nacional de Lanús, Remedios de Escalada.

PALACIOS, Juan Manuel y CANDIOTI, Magdalena (comps.). (2007). Justicia, política y derechos en América Latina. Buenos Aires: Prometeo.

WITTGENSTEIN, Ludwig (2004). Tractatus logico-philosophicus. Madrid: Alianza. 